УДК $81 ’ 342.3+378.016(07)$

DOI: $10.21779 / 2542-0313-2017-32-3-69-76$

\title{
И.М. Абакаров
}

\section{Обучение интонации при изучении иностранных языков как императив}

Дагестанский государственный университет; Россия, 367001, 2. Махачкала, ул. М. Гаджиева, 43a; migarbi@mail.ru

В статье теоретически обосновывается необходимость обучения иноязычной интонации при преподавании иностранных языков; анализируются лингвистические, психологические и педагогические особенности обучения иноязычной интонации; обозначаются трудности, встречающиеся в практике преподавания французской интонации; даются некоторые практические рекомендации.

Обучение интонации при постановке иноязычного произношения следует рассматривать как императив при подготовке будущих специалистов иностранного языка, поскольку без знания и владения интонационными составляющими неродного языка осуществление коммуникации невозможно. Отмечается, что выработка нормативной иноязычной интонации является наиболее сложной частью во всей совокупности слухо-артикуляционной работы над языком. Неправильная интонация мгновенно выдает иностранцев, даже в тех случаях, когда они правильно произносят звуки в словах и фразах. При работе над интонацией преподаватель может встретить ряд трудностей, что обусловлено факторами разного порядка: культурологического, психолого-педагогического, физиологического, которым даются соответствующие разъяснения. Особую роль при обучении иноязычной интонации следует отводить интонации эмоциональной речи, которая еще мало изучена. Лингвисты (фонетисты) не располагают какой-либо раз и навсегда научно обоснованной классификацией эмоциональной речи. Порой не всегда удается адекватно уловить подтекстовые коннотации даже в условиях живого общения на родном языке. А при коммуникации на иностранном языке данная задача становится на порядок сложнее еще и потому, что в этом случае на передний план выступает не только лингвистическая (просодическая), но еще и лингвоэтнокультурная (лингвоэтнокультурологическая) составляющая как вербальной, так и невербальной экспрессивной речи. И отрабатывать в искусственных языковых условиях иноязычную интонацию становится задачей чрезвычайной сложности.

Ключевые слова: интонационные навыки, мелодика, фонологический слух.

Целями данной статьи являются теоретическое обоснование необходимости обучения иноязычной интонации при преподавании иностранных языков, выявление лингвистических, психологических и педагогических особенностей обучения иноязычной интонации, обозначение трудностей, встречающихся при работе над «чужой» интонацией. В статье такие даются практические рекомендации при обучении, в частности, интонации французского языка.

Первое, что воспринимает человек при живой коммуникации, - это интонацию своего собеседника. При общении вся система языка как бы спрессована в различные типы интонации, в соответствующий мелодический рисунок фразы. И на первый взгляд нет вроде необходимости аргументировать всю важность овладения иноязычной интонацией при изучении иностранных языков. Тем не менее, процесс обучения интонации продолжает находиться в так называемом «свободном плавании». Говоря иначе, работа над выработкой иноязычной интонации пущена на самотек. Многие преподаватели по- 
лагают, что в рамках регулярно сокращаемых аудиторных часов и увеличивающихся в связи с этим часов на самостоятельную работу учащиеся способны овладеть интонационными навыками самостоятельно, опираясь на теоретические сведения, которые были им вкратце изложены преподавателем, а также на практические упражнения. Последние заключаются, как правило, в многократном и механическом повторении мелодических рисунков иноязычных фраз (текстов), воспроизводимых с видео- и аудионосителей. Их также можно найти в глобальной сети на определенных сайтах. Но в данном случае, во-первых, игнорируется очевидный факт необходимости преподавательского контроля во время выполнения практических упражнений, даже если учащийся обладает прекрасными имитативными способностями. В данном случае уместны слова выдающегося А. Леонтьева о том, что «учитель напрасно (подчеркнуто нами) надеется на то, что ученик - это такое устройство, которое все равно научится языку, как бы мы плохо его не учили» [8, с. 126]. А во-вторых, следует помнить, что будущий специалист в области иностранного языка должен работать не просто над интонационными рисунками восходящих и нисходящих тонов отрабатываемых им фраз, а усваивать чрезвычайно разнообразную мелодику живой эмоциональной речи.

Трудно, конечно, не согласиться с утверждением некоторых методистов о том, что полноценными интонационными навыками возможно овладеть лишь в естественных языковых условиях. Однако это вовсе не означает, что данное направление является второстепенной задачей. Работа над интонацией неотделим от всего процесса обучения слухо-произносительным навыкам. Обучение интонации должно занимать передовые позиции уже хотя бы потому, что данный процесс не может рассматриваться изолированно от процесса обучения коммуникативным навыкам, что является первоочередной задачей в преподавании иностранных языков. Уровень же современных педагогических и информационных технологий таков, что обучаемый легко получает доступ к самым передовым дидактическим ресурсам, позволяющим ему отрабатывать как сегментные, так и супрасегментные единицы в процессе изучения иностранных языков ${ }^{1}$. Однако повторим, что обучение интонации в процессе преподавания иностранных языков даже на спецфакультетах рассматривается не только как интегративный процесс, но и как отдельная и нередко второстепенная проблема. Специалисты не оспаривают необходимость и важность освоения иноязычной интонации в практике преподавания, но в силу некоторых объективных и субъективных причин не уделяют этому должного внимания и времени. Вместе с тем обучение интонации при постановке иноязычного произношения следует рассматривать как императив при подготовке будущих специалистов иностранного языка, поскольку без знания и владения интонационными составляющими неродного языка осуществление полноценной коммуникации невозможно. Существует немало примеров непонимания смысла высказывания из-за того, что оно было неправильно проинтонировано. Например, такую простую фразу, как “Pierre affirme mon père est parti" можно понять по-разному в зависимости от того, в какую мелодию мы облекаем отрезки данной фразы:

1. Mon père affirme | Pierre est parti $\|$ (Мой отец утверждает, что Петр уехал).

2. Mon père | affirme Pierre | est parti || (Мой отец, утверждает Петр, уехал).

В данном случае мелодика выступает как средство членения предложения в дополнение к ударению и служит основным фонетическим средством передачи отношений синтагм.

${ }^{1} \mathrm{O}$ дидактических ресурсах, особенностях и трудностях работы над интонацией речь пойдет ниже. 
Одновременно отметим, что овладение нормативной иноязычной интонацией является наиболее сложной работе во всей совокупности слухо-артикуляционной работы над языком. Неправильная интонация чаще всего выдает иностранцев даже в тех случаях, когда они правильно произносят звуки в словах и фразах. Сама же интонация является основным репрезентантом коммуникативного намерения говорящего и индикатором коммуникативных типов предложений [3, с. 10-13].

Необычное звучание незнакомых слов, мелодия ${ }^{2}$ привлекают вначале интерес учеников к изучаемому иностранному языку, но через некоторое время эта привлекательность снижается, а затем и вовсе пропадает, поскольку в сознании детей возникает эффект «дежа вю»: звуки незнакомые, но мелодия, создаваемая этими звуками, учащимся знакома. Другими словами, преподаватель прекрасно произносит все звуки иностранного языка, но облекает их в интонацию своего родного языка (русского, аварского, даргинского, лакского...). С данным обстоятельством автор встречался не раз в практике преподавания французского языка. Интонация, мелодия неродных фраз часто служит стимулирующим фактором при выборе учащимися иностранного языка. Не секрет, что, в частности, настоящая французская интонация обладает эффектом «обольщения» слушателя.

Следует помнить, что работа над интонацией в значительной степени способствует формированию навыков выразительного чтения, поскольку в этом случае обучаемый отрабатывает умение читать осмысленно, вникая в содержание и стилистику текста, пытаясь одновременно передать свойственное изучаемому языку интонацию.

Важность обучения супрасегментным навыкам следует рассматривать в трех плоскостях: лингвистической, психологической и педагогической.

С точки зрения лингвистической, в нашем случае сопряженной с основной задачей обучения иностранным языкам, то есть коммуникативной направленности процесса обучения, овладение интонационными навыками важно потому, что именно интонация позволяет передавать разнообразные коммуникативные модальности. Так, например, фраза "Il lui a acheté un gros bouquet de fleurs" может передать в зависимости от интонации констатацию, вопрос, сюрприз, восхищение, иронию и т. д. Незнание обучаемым способов декодирования семантических нюансов, передаваемых интонацией, может привести порой к противоположному пониманию того, что хотел сказать говорящий (см. вышеприведенный пример). И это несмотря даже на то, что обучаемый уже обладает достаточно высокими знаниями в изучаемом языке. Если эти знания позволяют ему пусть и при неточном интонировании нейтральных вариантов повествовательного и вопросительного предложений в ситуации реального общения быть правильно понятым, то отсутствие навыков правильного интонирования эмоциональных высказываний часто может ставить говорящего в неловкое положение. Известно, что эмоциональная составляющая высказываний в процессе общения имеет различные степени выраженности, что позволяет понять, гневается ли человек или радуется, удивляется или печалится. А такие нюансы, как сомнение, колебание, недоверие, раздражение и т. д., могут быть поняты только тогда, когда слушающий обладает достаточно богатым языковым опытом идентификации не просто эмоций, но и эмоциональных тонкостей.

С другой стороны, знание на слух так называемых интонационных контуров (кривых) иноязычной речи придает говорящему на иностранном языке определенную $n c u$ хологическую уверенность. Кроме того, адекватная интонация при говорении способ-

${ }^{2}$ В данной статье для удобства мы проводим знак равенства между терминами мелодия и интонация. 
ствует социальной интеграции, а это становится чрезвычайно актуальным при нынешних миграционных процессах жителей стран третьего мира в западные страны. Известно, что человеку хорошо говорящему на иностранном языке с точки зрения правильной реализации звукового строя на сегментном уровне, но «хромающему» на супрасегментном (неправильная акцентуация, ритмика, мелодика...), очень сложно стать «своим» в новом для него социуме. Если говорить образно, то насколько долго мы готовы слушать человека, который фальшиво поет? Если же речь иностранца близка к интонации родного языка говорящего, то риск быть «разоблаченным» незначителен. Автору не раз приходилось убеждаться в этом на практике. Носители языка могут простить ваши лексические, грамматические и стилистические погрешности, поскольку они сами их часто допускают, но звуковое искажение их родного языка, как правило, не прощается. Хотя вполне вероятно, что вслух это вам никто не скажет.

Есть еще одна особенность обучения иноязычной интонации - педагогическая. Самое первое, что воспринимает обучаемый, - это интонация. Не слова и словосочетания, а их мелодическую оболочку. Причем восприятие в данном случае должно рассматриваться глобально: обучаемый воспринимает так называемые звуко-блоки, разделенные подъемами и падениями голоса (восходящими и нисходящими тонами), особой, свойственной каждому языку акцентуацией, различного типа паузами. Именно интонация позволяет делить звуковой континуум на соответствующие отрезки, которые часто могут совпадать со смысловыми отрезками. Именно она составляет тот фон, без которого реализация сегментных единиц (фонем) была бы невозможна. Правильное восприятие и реализация звуковой единицы зависят от ее места внутри ритмикоинтонационного движения.

Однако, работая над интонацией, преподаватель наталкивается, как правило, на определенные трудности, обусловленные факторами разного порядка, во-первых, и это очень часто - культурологического. Каждый язык, обладает своей собственной динамичной интонационной структурой, которая формируется и закрепляется в речевом сознании индивида в результате практики социально-коммуникативного общения с самого раннего детства. Интонация неразрывно связана с мимикой и жестами и сопровождает каждое речевое действие. А мимика и жесты во многом различны в культуре каждого народа. Таким образом, при преподавании иноязычной интонации следует помнить о соответствующих жестах и мимике, которые свойственны определенной интонации.

Следующая трудность обусловлена психолого-педагогическим фактором. Известно, что ребенок овладевает интонацией задолго до освоения фонологической системы, поскольку внутриутробный плод способен воспринимать мелодику речи матери и постоянно окружающих ее людей начиная с возраста нескольких месяцев (конца шестого месяца?), а новорожденный, что уже общеизвестно, способен отличать голос (интонацию) своей матери от интонации других людей. И во взрослом возрасте, когда интонация становится чем-то вроде лингвистического «ЭГО» человека, вторжение в это «ЭГО» чуждой языковой интонации встречает нередко сопротивление, поскольку некоторые обучаемые начинают при этом испытывать дискомфорт, что легко обнаруживается на занятиях по практической фонетике французского языка, когда автор при заучивании диалогов регулярно пытается смоделировать необычную для студентов французскую интонацию. С этим связана и такая трудность психологического плана, как тип личности обучаемого. Студенты-экстраверты легче поддаются обучению иноязычной интонации, чем студенты-интроверты. 
Еще одна трудность - физиологического плана. Не секрет, что у каждого индивида уровень слухового восприятия свой, то есть свой семантический декодер, способный слышать (не слышать) смысловые нюансы, передаваемые интонацией носителя изучаемого языка. И очень часто этот семантический декодер дает сбой, когда следует проанализировать такие параметры интонации, как длительность, высота и интенсивность, лежащие в основе реализации соответствующего речевого ритмико-мелодического рисунка.

Все эти трудности должны решаться с помощью длительных и тщательных тренировок. И здесь каждый преподаватель иностранного языка выбирает свой путь в зависимости от его профессионализма, педагогического опыта и мастерства.

Приведем лишь несколько практических рекомендаций на самом первом этапе работы над интонацией французского языка. Во-первых, следует начинать с диагностики его фонологического слуха (conscience phonologique) учащегося, которая заключается в проверке его умений правильно не только различать на слух ксенозвуки, но и воспринимать некоторые супрасегментные характеристики звучащей речи (восходящий тон), нисходящий тон, определять различные типы коммуникативных фраз и т. д. Но следует помнить, что для отработки той или иной фонемы недостаточно работать с упражнениями, основывающимися на бинарных оппозициях. Этим самым навык не приобретается. Здесь просто проверяется его фонологический слух. В данном случае необходимо тренировать мелодический слух, тренируясь на специальных упражнениях, коммуникативно наполненных. И поэтому (во-вторых) нужно предлагать слушать учащимся только высказывания реального общения. Пусть они будут сначала короткими. При этом работать не с отдельными звуками или слогами, а как минимум с ритмическими группами. То есть для работы над интонацией следует обязательно разделять высказывание на ритмические группы, а затем приступать к прогрессивному и регрессивному повтору. При прогрессивном повторе обучаемый увеличивает количество ритмических групп, идя слева направо. При регрессивном повторе количество ритмических групп также возрастает, но уже справа налево. Это так называемые упражнения на увеличение длины синтагмы. Например, фраза Tu pars à Paris jeudi soir? при прогрессивном повторе будет разбита следующим образом:

Tu pars? $\nearrow$

Tu pars à Paris? $\nearrow$

Tu pars à Paris jeudi ?

Tu pars à Paris jeudi soir? $\nearrow$;

при регрессивном повторе разбивка будет:

Soir? $\nearrow$

Jeudi soir? $\nearrow$

Paris jeudi soir? $\nearrow$

À Paris jeudi soir? $\nearrow$

Pars à Paris jeudi soir? $\nearrow$

Tu pars à Paris ? $\nearrow$

При регрессивном повторе количество элементов для повтора возрастает.

Вот еще несколько примеров.

Прогрессивный повтор с понижением тона:

Je prends du café $\| \curvearrowright$.

Je prends du café $\mid$ avec du pain $\| \curvearrowright$

Je prends du café au lait $\mid$ avec du pain $\| \curvearrowright$ 
Je prends du café au lait | avec du pain, du beurre et du fromage $\| \curvearrowright$ Регрессивный повтор значительно увеличивает количество повторяемых элементов:
Fromage $\curvearrowright$
Du fromage $\curvearrowright$
Et du fromage $\curvearrowright$
Beurre et du fromage $\curvearrowright$
Du beurre et du fromage $\curvearrowright$
Pain, du beurre et du fromage $\curvearrowright$
Du pain, du beurre et du fromage $\curvearrowright$
Avec du pain, du beurre et du fromage $\curvearrowright$
Lait avec du pain, du beurre et du fromage $\curvearrowright$
Au lait avec du pain, du beurre et du fromage $\curvearrowright$
Café au lait avec du pain, du beurre et du fromage $\curvearrowright$
Du café au lait avec du pain, du beurre et du fromage $\curvearrowright$
Prends du café au lait avec du pain, du beurre et du fromage $\curvearrowright$
Je prends du café au lait avec du pain, du beurre et du fromage $\curvearrowright$

Эмоциональная речь еще мало изучена. Лингвисты (фонетисты) не располагают какой-либо раз и навсегда научно обоснованной классификацией эмоциональной речи, которая очень разнообразна и не поддается укладке в прокрустово ложе готовых схем, в силу ее чрезвычайной модальности, отсутствия нейтральности, с трудноуловимыми смысловыми нюансами и подтекстами. Порой не всегда удается адекватно уловить подобные подтекстовые коннотации даже в условиях живого общения на родном языке. А при коммуникации на иностранном языке данная задача становится на порядок сложнее еще и потому, что в этом случае на передний план выступает не только лингвистическая (просодическая), но еще и лингвоэтнокультурная (лингвоэтнокультурологическая) составляющая как вербальной, так и невербальной экспрессивной речи. И отрабатывать в искусственных языковых условиях иноязычную интонацию становится архисложной и почти неразрешимой задачей. В свое время автор сделал попытку обратиться к известному французскому блогеру Жану Соммеру (Jean Sommer) www.jeansommer.fr, специализирующемуся в области обучения французскому языку, с просьбой посоветовать некоторые конкретные дидактические видео- и аудиодокументы, посвященные обучению французской интонации, в частности интонации живой речи (intonation des sentiments), и которые были бы привязаны к конкретным типам эмоций (радость, грусть, удивление, негодование, гнев, сожаление и т. д.). Однако Жан Соммер посоветовал присоединиться к его блогу, где он был готов предложить несколько упражнений по интересующему меня вопросу. Это лишь подтверждает вышесказанное о том, что нет готовых схем по обучению французской эмоциональной интонации, что она привязана к конкретной речевой ситуации, и самое лучшее обучение интонации живой речи на иностранном языке - это естественная языковая среда. Пытаться же смоделировать естественную языковую среду могут себе позволить только самые передовые языковые вузы страны, в силу не только лучшего технического оснащения, но и наличия возможности привлекать к процессу моделирования нормативных носителей иностранного языка. Тем не менее, нельзя ни в коем случае игнорировать процесс выработки иноязычных интонационных навыков в рамках учебных часов. Помимо тренировочных упражнений, указанных нами выше и которые можно найти в различных 
учебниках, решению этой задачи в значительной степени может способствовать интернет. Но следует всегда помнить, что для отработки мелодики живой французской речи следует обращаться лишь к оригинальным видео- и аудиоисточникам, которые, хоть и не дидактизированы, но могут все же послужить неплохими упражнениями для имитации мелодики при работе над различными интонационными рисункам.

\section{Литература}

1. Абакаров И.М. Фонологический слух при контактировании трех разносистемных языков (экспериментально-фонетическое исследование на материале даргинского, русского и французского языков): автореф. дис. ... к. филол. н. - СПб., 1992.

2. Абрамова И.Е. Фонетическая вариативность вне естественной языковой среды. Монография. - М.: Флинта, 2015. - 288 с.

3. Артемов B.A. Метод структурно-функционального изучения речевой интонации. - М.: МГПИИЯ им. М. Тореза, 1974. - 164 с.

4. Венцов А.В., Касевич В.Б. Проблемы восприятия речи. - СПб.: Изд-во СанктПетербургского университета, 1994. - 232 с.

5. Горбенко Е.Л. Формирование фонематического слуха у дошкольников, имеющих речевые нарушения // Теория и практика образования в современном мире; материалы Межд. науч. конф. - СПб., 2012. - С. 262-264.

6. Зиндер Л.Р. Общая фонетика. - М.: Высшая школа, 1979. - 312 с.

7. Кудасова Н.В. Формирование речевого слуха на начальном этапе обучения русскому языку // Материалы Межд. научно-практич. конфер. «Проблемы преподавания профессионально ориентированного иностранного языка в вузе». - Рязань, 2014. C. $103-106$.

8. Леонтьев А. Обучение умениям педагогического общения и проблема подготовки преподавателей русского языка как иностранного // Тезисы докладов и сообщений;

IV Международный конгресс преподавателей русского языка и литературы. - Берлин, ГДР, 1979. - С. 126.

9. Лобанов B.A. Фонологическая интерференция слуха при восприятии односложных слов русского языка носителями разносистемных языков // Международный журнал экспериментального образования. - 2016. - Вып. № 3-2. - С. 300-304.

10. Михайленко Л.Г. Соотношение фонетического и фонологического аспектов при обучении иноязычному произношению // Новая наука: опыт, традиции, инновации. - Уфа: ООО «Агентство международных исследований», 2016. - № 4-3. - С. 104-106.

11. Светозарова Н.Д. Интонационная система русского языка. - Л., 1982.

12. Скорек Ю. К вопросу исследования, изучения и обучения интонации русского, польского и немецкого языков как иностранных (экспериментальные исследования) // Rocznik Instytutu Polsko-Rosyjskiego. - 2014. - Nr 2.

13. Фахретдинова A.A. Особенности развития фонетико-фонематической стороны речи у детей дошкольного возраста со стертой дизартрией // Научно-методический электронный журнал «Концепт». - 2014. - Т. 20. - С. 2931-2935. - URL: http://ekoncept.ru/2014/54850.htm.

14. Шмыгун М.A. Формирование фонематического восприятия у детей дошкольного возраста с нарушением речи // Филологическое образование в период детства. Екатеринбург: Уральский государственный педагогический университет, 2015. T. 22.- C. 99-102. 
15. Harmegnies, B., Delvaux, V., Huet, K., Piccaluga M. Oralité et cognition: pour une approche raisonnée de la pédagogie du traitement de la matière phonique // Revue Parole. 2005. Vol. 34-36. - P. 336.

Поступила в редакицию 10 октября 2017 г.

UDC 81’342.3 + 378.016(07)

DOI: $10.21779 / 2542-0313-2017-32-3-69-76$

Teaching intonation when studying foreign languages as an imperative

\section{I.M. Abakarov}

Dagestan State University; Russia, 367001, Makhachkala, M. Gadzhiyev st., 43a; migarbi@mail.ru

The article theoretically substantiates the necessity of teaching intonation in the teaching of foreign languages. Linguistic, psychological and pedagogical features of teaching foreign language intonation are analysed; the difficulties of teaching French intonation are marked as well as some practical recommendations are given when teaching the intonation of the French language.

Learning intonation should be regarded as imperative in preparing future specialists of foreign language as the process of communications is impossible without intonation skills of non-native language. It is noted that the mastery of normative foreign language intonation is the most difficult work in the overall auditory-articulatory work of the language. A wrong intonation most often gives up foreigners, even if they pronounce words and sentences correctly. Teaching intonation a teacher can come across some difficulties due to different factors: cultural, psycho-pedagogical, physiological the article gives appropriate explanations. A special role in the teaching of intonation should be paid to the intonation of emotional speech, which is still poorly understood. Linguists do not have a unified scientifically based classification of emotional speech. It is not always possible to adequately capture subtext connotations even in the context of live communication in their native language. When communicating in a foreign language this task becomes far more complicated due to ethnocultural as well as linguistic (prosodic) component of both verbal and non-verbal expressive speech. Teaching foreign language intonation in artificial language conditions becomes a task of extreme complexity.

Keywords: intonation skills, melody, phonological hearing.

Received 10 October, 2017 